\title{
Status of physical health of elderly living with children and in empty nest families: An in-depth study
}

Received: 19.05.2017; Revised: 16.09.2017; Accepted: 02.10.2017

See end of the paper for authors' affiliations JATINDER K. GULATI Department of Human Development, Punjab Agricultural University, LUDHIANA (PUNJAB) INDIA Email : jkgulati@pau.edu
ABSTRACT : Ageing is a part of living. Poor health is often observed as one of the most serious problems in old age. Therefore by keeping the health concern of elderly in mind the study aimed to study in detail the Status of Physical health of elderly living with children and in empty nest families was conducted on a sample of 120 elderly man and women with children and in empty nest families, randomly selected from three chosen localities of Ludhiana city. The objective of the study was to assess the status of physical well-being of the elderly living with married children and in empty nest families. The results revealed that the level of different types of physical health problems on the whole was low among elderly men and women living in both the settings. However, the elderly parenting living in empty nest families were suffering from higher number of physical health problems as compared to them living with children.

KEY WORDS: Ageing, Physical health, Parenting, Empty nest, Problems

- HOW TO CITE THIS PAPER : Gulati, Jatinder K. and Kaur, Samreet (2017). Status of physical health of elderly living with children and in empty nest families: An in-depth study. Asian J. Home Sci., 12 (2) : 320-327, DOI: 10.15740/HAS/AJHS/12.2/320-327. 